\title{
CONTRIBUTORS AND CONTRIBUTORS' SECRETARIES PLEASE NOTE!
}

Modern technology is marvellous but is not necessarily accompanied by improving eyesight. Manuscripts produced on word processors or microcomputers with dot matrix printers are not acceptable. Copy which is "dot printed" is difficult to read (referees and editorial staff), almost impossible to edit (editorial staff) and creates undue eyestrain on keyboard operators at the printers.

All manuscripts to be considered must be typed or printed on "letter quality" typewriters or printers. If not they will be returned for retyping or, in extreme cases, rejected on the grounds of unreadability.

While on the subject of presentation may I urge all concerned with submitting a paper to Journal of Helminthology to read, and act upon, the instructions to authors.

Essential, basic requirements are: typing all sections with double spacing and wide margins all round. Justification of the righthand margin is not required, is uneconomical and can be a source of error. References must be complete and in the correct form. At least two (preferably three) copies of the paper and illustrations should be sent to the Editor, all on good quality paper.

If you do not have a copy of our "Instruction to Contributors" to keep on your desk we will supply one on request. Attention to the instructions given will save time in the long run. 